\title{
Association study of genetic variants in eight genes/loci with type 2 diabetes in a Han Chinese population
}

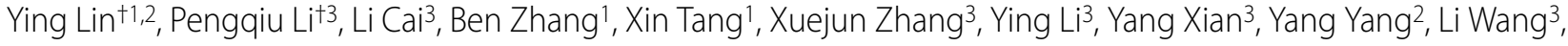

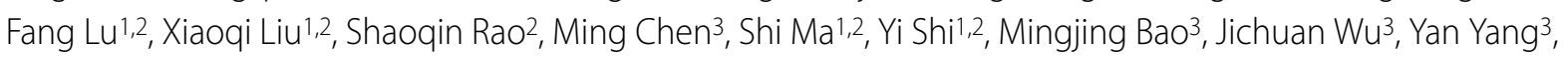 \\ Jiyun Yang ${ }^{1,2}$ and Zhenglin Yang*1,2
}

\begin{abstract}
Background: At least twenty genes/loci were shown to be associated with type 2diabetes in European original populations. Five of these genes were shown to be associated with type 2 diabetes (T2D) in Chinese populations. The purpose of this study was to replicate the association of genetic vairants in the eight diabetes-related genes/loci with type 2 diabetes in a Han Chinese cohort from western part of China. Nineteen single nucleotide polymorphisms (SNPS) from the eight genes/loci including TCF7L2, HHEX, CDKAL1, SLC3OA8, PPARG, IGF2BP2, KCNJ11, and CDKN2A/CDKN2B were genotyped in 1,529 cases and 1,439 controls in a Han Chinese population using the ABI SNaPshot method. The metaanalysis of the association between rs7903146 in TCF7L2 gene and T2D in the Han Chinese was performed.

Results: Among the eight genes/loci examined, we found that four were significantly associated with T2D. Although previous studies showed that the association between the SNP rs7903146 in the TCF7L2 gene and T2D was controversial within the Han Chinese population, we have confirmed the significant association between the SNP rs7903146 in the TCF7L2 gene and T2D in both this study and the meta-analysis in the population. In addition, we also confirmed that three SNPs (rs1111875, rs7923837 and rs5015480) in HHEX, one SNP (rs10946398) in CDKAL1, and three SNPs (rs13266634, rs3802177 and rs11558471) in SLC30A8 were significantly associated with T2D in the population being studied.
\end{abstract}

Conclusions: We demonstrated that the variants in TCF7L2, CDKAL1, HHEX, and SLC30A8 genes are associated with T2D in a Han Chinese population.

\section{Background}

Diabetes is characterized as hyperglycemia that occurs when the pancreas does not produce enough insulin, or when the body cannot effectively use the insulin it produces. Globally, diabetes causes about $5 \%$ of all deaths each year; this statistic is likely to increase by more than $50 \%$ in the next ten years without urgent action http:// www.who.int/diabetes/en. In China, it is estimated that the number of diabetes patients will increase from the previous figure of 20.8 million in 2000, to 42.3 million in 2030 [1]. Type 2 diabetes (T2D) is the most common

\footnotetext{
* Correspondence: zliny@yahoo.com

1 Center for Human Molecular Biology \& Genetics, Sichuan Academy of Medical Sciences \& Sichuan Provincial People's Hospital, Chengdu, Sichuan, China + Contributed equally

Full list of author information is available at the end of the article
}

form of diabetes, which is caused by an interaction of multiple genes and environmental factors.

Previous linkage studies and candidate gene approaches have identified several genes associated with T2DM, such as CAPN10, ENPP1, HNF4A, ACDC, PPARG, and KCNJ11 [2-8]. The TCF7L2 gene, initially mapped by a linkage study, is the strongest known T2D association gene in European original populations [9]. Whole genome association studies (WGAS) offer a new approach to gene discovery for T2D. For example, genetic variants in more than 15 genes/loci including CDKN2A/ $B$, CDKAL1, SLC30A8, IGF2BP2, HHEX/IDE, FTO, KCN1, NOTCH2, CDC123/CAMK1D, ADAMTS9, THADA, TSPAN8/LGR5, JAZF1, MTNR1B and IRS genes, have been showed to be associated with T2D by 
genome-wide association studies (GWAS) [10-19]. Although more and more T2D associated gene/loci are being identified, the replication study has played a critical role in confirming the reported $\mathrm{T} 2 \mathrm{D}$ associated genes/ loci, especially within different ethnic populations. Among the T2D genes/loci, single nucleotide polymorphisms (SNPs) in CDKAL1, CDKN2A/B, IGF2BP2, $S L C 30 A 8$, and $H H E X / I D E$ genes were also shown to have an association with T2D in two Chinese cohorts [20-23]. The association between rs7903146 in the TCF7L2 and T2D in the Chinese population is still considered to be controversial in Han Chinese populations from north, east and south China [24-27]. In this study, we examined the associations of nineteen SNPs in eight T2D genes/loci in a Han Chinese population in western part of China.

\section{Methods}

\section{Subjects}

This study was approved by the Clinical Research Ethics Committee of the Sichuan Academy of Medical Sciences \& Sichuan Provincial People's Hospital. All subjects provided informed consent prior to participation in the study. Diabetes patients were recruited in the diabetes clinic at Sichuan Academy of Medical Sciences \& Sichuan Provincial People's Hospital. Included were 1,529 diabetic cases and 1,439 non-diabetic controls. Diabetes was diagnosed in accordance with the criteria of the World Health Organization [28]. There was not exposure to glucoselowering treatment for the controls, controls with a fasting plasma glucose concentration $<5.6 \mathrm{mmol}$ were enrolled from the same geographical region. The age of the patients, body mass index (BMI), SBP, DBP, GLU, TC, TG, LDL, HDL, HbA1c, and duration of T2D were recorded. All cases and controls were Han Chinese from Chengdu area of China. The basic characteristics of the cases and controls are listed in Table 1.

\section{Genotyping}

The Han Chinese series of 1,529 diabetic patients was genotyped and allele frequencies were compared to 1,439 ethnicity-matched non-diabetic control subjects by lab personnel blinded to case/control status. The DNA was isolated from white blood cells using the phenol/chloroform and ethanol precipitation method. SNPs in eight genes/loci from the first round of European GWASs were analyzed in this study, most significant SNPs in the GWASs or in the replication studies in East Asians were selected to perform genotyping. Nineteen SNPs in eight genes/loci were genotyped using the ABI SNapShot method (Applied Biosystem, CA, USA). In brief, PCR was performed using specific PCR primers; the specific $\mathrm{SNaPshot}$ primer was used for a SNaPshot reaction using the purified PCR products as templates. The SNaPshot reaction products were then analyzed on an ABI 3130
Genetic Analyzer (Applied Biosystem, CA, USA). All PCR and SNaPshot primers are listed in Additional file 1. To confirm the genotyping results, $10 \%$ of the samples were randomly selected and re-genotyped by direct sequencing using a BigDye terminator (Applied Biosystem, CA, USA); no more than a $2 \%$ discrepancy was observed in all SNPs between the two genotyping methods.

\section{Statistical Analysis}

Continuous variables were described as mean $\pm \operatorname{std}(\bar{x} \pm$ $s$ ) or quartiles $\left(P_{25}, M\right.$, and $\left.P_{75}\right)$ for data with and without normality, respectively, and were tested by a Student $t$ test. Categorical variables such as gender (male vs. female) were analyzed using a Chi-square test.

We tested the Hardy-Weinberg equilibrium (HWE) for each SNP separately in both the case and control populations by using the Fisher's exact method, as reported by Emigh, et al. [29]. Linkage disequilibrium $(L D)$ coefficients $\left(r^{2}\right.$ and $\left.D^{\prime}\right)$ were computed by using Haploview 4.1 http://www.broad.mit.edu/haploview.

A standard chi-square test with a 1-degree-of-freedom (df) was used to calculate the differences of allele frequencies for each SNP between the case and control group. Odds ratios (ORs) with 95 percent confidence intervals ( $\mathrm{CIs}$ ) were assessed for the risk allele of each SNP based on a multiplicative model. For the genotypes, we tested a series of genetic models including additive, dominant/recessive for the SNPs with a $p$ value of $<0.05$ of allelic, trend test by using unconditional logistic regression with adjustment for age, gender, and body mass index (BMI).

SAS 9.1 (SAS Institute Inc., Cary, NC, USA) was used to process the data. Results were confirmed by $\mathrm{R} 2.7 .2$ http://cran.r-project.org/; a two-sided P value $<0.05$ was considered statistically significant unless stated otherwise. Different genetic models, including dominant and recessive model, were evaluated through pearson $X^{2}$ test by comparing genotypic counts between cases and controls. Allelic $\mathrm{p}$ value is obtained by comparing the allele frequency difference in cases and controls under the assumption of a multiplicative model. An additive model is tested using Armitage's test for a trend [30].

\section{Meta-analysis of the association between rs7903146 in the TCF7L2 gene and T2D in the Han Chinese population}

We obtained the data for rs7903146 in the TCF7L2 gene in Han Chinese populations by searching Pub Med using key words of TCF7L2, Han Chinese, and Diabetes $[21,24,25,31]$. Additional four association studies representing four different parts of China were included in this meta-analysis. The data was then combined with our data 
Table 1: Characteristics of cases and controls for age and ethnicity

\begin{tabular}{llll}
\hline Variables & $\begin{array}{l}\text { Subject group } \\
\text { Cases }(\mathbf{n}=\mathbf{1 5 2 9})\end{array}$ & Controls (n= 1439) & p value \\
& & & \\
\hline Age at test (years) & $60.2 \pm 10.1$ & $58.1 \pm 10.8$ & $<0.001$ \\
Gender (male \%) & 47.8 & 50.0 & 0.225 \\
BMI (kg/m2) & $23.9 \pm 2.7$ & $23.5 \pm 2.8$ & $<0.001$ \\
SBP (mmHg) & $136.1 \pm 12.0$ & $123.9 \pm 16.0$ & $<0.001$ \\
DBP (mmHg) & $80.04 \pm 6.8$ & $76.7 \pm 9.3$ & $<0.001$ \\
GLU(mmol/L) & $8.3 \pm 2.7$ & $4.9 \pm 0.6$ & $<0.001$ \\
TC (mmol/L) & $5.22 \pm 0.77$ & $5.17 \pm 0.87$ & 0.139 \\
TG (mmol/L) & $2.09 \pm 1.45$ & $1.45 \pm 1.14$ & $<0.001$ \\
LDL (mmol/L) & $3.10 \pm 0.85$ & $3.08 \pm 0.81$ & 0.497 \\
HDL (mmol/L) & $1.40 \pm 0.74$ & $1.41 \pm 0.30$ & 0.822 \\
HBA1C (\%) & $7.97 \pm 0.73$ & $/$ & $/$ \\
DURATION (years) & $8.73 \pm 4.57$ & $/$ & $/$ \\
\end{tabular}

Data are shown as mean $\pm S D$; The $p$ values were obtained by comparison of cases and controls

in this study and the $\mathrm{p}$ value and OR were calculated under the assumption of a multiplicative model. A total of 3203 cases and 3109 controls of Han Chinese population for rs7903146 in the TCF7L2 gene were included in this meta-analysis (Table 2).

\section{Results}

We genotyped nineteen representative SNPs in eight potential T2D genes/loci a Han Chinese population, comprised of 1,529 cases and 1,429 controls. All SNP were within Hardy-Weinberg equilibrium in controls $(\mathrm{P}>$ 0.05 , Table 3). Linkage disequilibrium (LD) analysis of SNPs genotyped for each gene/locus demonstrated that SNPs in SCL3OA8 and PPARG genes, but not in other genes, were at the same LD, respectively (Table 3).Three SNPs in the SCL30A8 gene were at the same LD with $D^{\prime}$ of 0.95 to 0.99 , but they were not completely at the same LD because the $r^{2}$ was less than 0.8 from 0.55 to 0.67 . Three SNPs in the PPARG gene were also showed at the same LD with $D^{\prime}$ from 0.7 to 0.89 , but they were not strongly at the same LD because of lower $r^{2}(0.022$ to 0.38$)$ (Table 3).

SNPs in four genes including TCF7L2, CDKAL1, SLC3OA8 and HHEX/IDE showed significant association with T2D in the studied cohort even after a stringent Bonferroni correction (adjust $\mathrm{p}$ values $<0.05$, Table 3 ). One SNP (rs7903146) in the TCF7L2 gene, and three SNPs (rs1111875, rs7923837 and rs5015480) in the HHEX gene showed significant association with T2D both in multiplicative and dominant models (adjusted $\mathrm{p}<$ 0.027 , Table 3). In addition, one SNP (rs10946398) in the CDKAL1 gene and three SNPs (rs13266634, rs3802177 and rs11558471) in the SLC30A8 gene showed significant association with $\mathrm{T} 2 \mathrm{D}$ in multiplicative, dominant and recessive models (adjusted $\mathrm{p}<0.0026$, Table 3 ). The rs10946398 in CDKAL1 had the strongest association with $\mathrm{T} 2 \mathrm{D}$, the frequency of allele $\mathrm{T}$ was 0.45 in case subjects and 0.37 in control subjects. Individuals with risk allele $\mathrm{T}$ of rs10946498 conferred a 1.78 fold (95\% CI: 1.46 2.17) of increased likelihood of T2D (adjust $\mathrm{p}=6.26$ $\times 10^{-9}$ ) with recessive model (Table 3 ). In the studied cohort, no association with T2D was found in the typed SNPs in the four potential T2D genes/loci, including PPARG, IGF2BP2, KCNJL1, and CDKN2A/B (Table 3).

Meta-analysis of rs7903146 in the TCF7L2 gene with T2D in four cohorts of Han Chinese populations composed of 3,203 cases and 3,109 controls also supported that rs7903146 in the TCF7L2 was significantly associated with $\mathrm{T} 2 \mathrm{D}$ in the Han Chinese population (trend $\mathrm{p}=$ $\left.6.2 \times 10^{-4}\right)$ with OR of 1.37 .

\section{Discussion}

The Chinese population accounts for approximately 20 percent of the world's population. The replication study of T2D genes/loci in this population has expanded the genetic investigation of T2D in a large ethnic group. Previous association studies of genetic variants in the eight genes and T2D of the Han Chinese populations were from Hong Kong (south), east and north China. The Chinese population of this study was taken from a Han Chinese population in western part of China. Because significant differences exist among Han Chinese subpopulations in China [32,33], the population in this study represented a different type of Han Chinese subpopulala- 
Table 2: Meta-analysis of rs7903146 in TCF7L2 with T2D in the Han Chinese populations

\begin{tabular}{|c|c|c|c|c|c|c|c|c|c|c|c|c|c|c|}
\hline \multirow{3}{*}{ Authors } & \multirow{3}{*}{ Samples collected } & \multirow{3}{*}{ References } & \multicolumn{8}{|c|}{ Genotyping count } & \multirow{2}{*}{\multicolumn{2}{|c|}{\begin{tabular}{|c|} 
Allele frequency \\
Risk allele (T)
\end{tabular}}} & \multicolumn{2}{|c|}{ Multiplicative model } \\
\hline & & & \multicolumn{4}{|c|}{ Cases } & \multicolumn{4}{|c|}{ Controls } & & & \multirow[b]{2}{*}{$p$ value } & \multirow[b]{2}{*}{ OR $(95 \% \mathrm{Cl}) \mathrm{b}$} \\
\hline & & & Total N & CC & Ст & TT & Total N & CC & Ст & TT & Case & Control & & \\
\hline Ren et al & Beijing (North China) & 24 & 481 & 438 & 41 & 2 & 491 & 463 & 26 & 2 & 0.047 & 0.03 & 0.063 & $1.93(1.13-3.49)$ \\
\hline $\mathrm{Ng}$ et al & Hong Kong (South China) & 27 & 433 & 408 & 24 & 1 & 419 & 399 & 20 & 0 & 0.031 & 0.024 & 0.17 & $1.29(0.90-1.87)$ \\
\hline Chang et al & Taiwan (East China) & 25 & 760 & 724 & 35 & 1 & 760 & 716 & 44 & 0 & 0.024 & 0.029 & 0.36 & $0.81(0.50-1.31)$ \\
\hline Lin et al & Chengdu (West China) & This study & 1529 & 1348 & 178 & 3 & 1439 & 1328 & 107 & 4 & 0.060 & 0.040 & 0.00038 & $1.54(1.21-1.95)$ \\
\hline Combined all & Han Chinese in China & & 3203 & 2918 & 278 & 7 & 3109 & 2906 & 197 & 6 & 0.046 & 0.034 & 0.00058 & $1.37(1.15-1.65)$ \\
\hline
\end{tabular}




\begin{tabular}{|c|c|c|c|c|c|c|c|c|c|c|c|c|c|c|}
\hline \multirow[t]{2}{*}{ Gene } & \multirow[t]{2}{*}{ SNP } & \multirow[t]{2}{*}{ No. } & \multirow[t]{2}{*}{ LDa D'(r2) } & \multicolumn{2}{|c|}{ P value for HWEb } & \multicolumn{2}{|c|}{ Allel Frequency } & \multicolumn{7}{|c|}{ Additive model } \\
\hline & & & & Cases & Controls & Cases & Controls & Trend $\mathrm{p}$ value & Adjusted $\mathrm{p}$ value & ORc $(95 \% \mathrm{Cl}) \mathrm{d}$ & Adjusted $p$ value & OR $(95 \% \mathrm{Cl})$ & $\begin{array}{l}\text { Adjusted } \\
\text { p value }\end{array}$ & OR $(95 \% \mathrm{Cl})$ \\
\hline \multirow[t]{3}{*}{ TCF7L2 } & rs6585205 (T) & 1 & 1 vs $2: 0.28(0.0070)$ & 0.54 & 0.31 & 0.43 & 0.39 & 0.003 & 0.055 & & $4.0 \times 10^{-4}$ & $1.31(1.13,1.53)$ & 0.287 & $1.11(0.92,1.35)$ \\
\hline & rs7903146 (T) & 2 & 1 vs $3: 0.72(0.33)$ & 0.25 & 0.24 & 0.06 & 0.04 & $3.6 \times 10^{-4}$ & 0.007 & $1.54(1.19,1.99)$ & 0.001 & $1.58(1.25,2.03)$ & 0.691 & $1.41(0.40,5.02$ \\
\hline & rs11196218 (A) & 3 & 2 vs $3: 0.28(0.01)$ & 0.26 & 0.60 & 0.29 & 0.30 & 0.520 & 9.880 & & & & & \\
\hline \multirow[t]{3}{*}{ HHEX } & rs1111875 (G) & 4 & 5 vs $4: 0.39(0.11)$ & 0.11 & 0.32 & 0.32 & 0.28 & 0.001 & 0.016 & $1.11(0.97,1.27)$ & 0.005 & $1.23(1.07,1.42)$ & 0.011 & $1.43(1.08,1.89$ \\
\hline & rs7923837 (G) & 5 & 5 vs $6: 0.53(0.18)$ & 0.24 & 0.99 & 0.30 & 0.25 & $1.4 \times 10^{-5}$ & $2.7 \times 10^{-4}$ & $1.08(0.93,1.25)$ & $8.6 \times 10^{-6}$ & $1.39(1.20,1.61)$ & 0.062 & $1.30(0.99,1.72$ \\
\hline & rs5015480 (C) & 6 & 4 vs $6: 0.69(0.21)$ & 0.69 & 0.41 & 0.21 & 0.17 & 0.001 & 0.027 & $1.20(0.96,1.54)$ & $3.3 \times 10^{-4}$ & $1.32(1.14,1.54)$ & 0.657 & $1.08(0.75,1.59$ \\
\hline \multirow[t]{3}{*}{ CDKLA1 } & rs736425 (C) & 7 & 8 vs 9: $0.55(0.056)$ & 0.48 & 0.93 & 0.07 & 0.07 & 0.782 & 14.849 & & & & & \\
\hline & rs10946398 (C) & 8 & 7 vs $8: 0.11(0.0011)$ & 0.79 & 0.36 & 0.45 & 0.37 & $1.2 \times 10^{-9}$ & $2.2 \times 10^{-8}$ & $1.36(1.20,1.55)$ & $2.7 \times 10^{-6}$ & $1.44(1.24,1.68)$ & $6.3 \times 10^{-9}$ & $1.78(1.46,2.17)$ \\
\hline & rs4712527 (G) & 9 & 7 vs $9: 0.086(0.0020)$ & 0.07 & 0.52 & 0.22 & 0.21 & 0.270 & 5.132 & & & & & \\
\hline \multirow[t]{3}{*}{ SCL30A8 } & rs13266634 (C) & 10 & 10 vs $110.99(0.55)$ & 0.13 & 0.08 & 0.59 & 0.54 & $1.4 \times 10^{-4}$ & 0.003 & $1.37(1.20,1.56)$ & 0.005 & $1.32(1.09,1.60)$ & 0.001 & $1.31(1.11,1.53$ \\
\hline & rs3802177 (C) & 11 & 10 vs $120.95(0.64)$ & 0.96 & 0.15 & 0.60 & 0.53 & $9.9 \times 10^{-8}$ & $1.9 \times 10^{-6}$ & $1.33(1.18,1.52)$ & 0.007 & $1.29(1.07,1.57)$ & $1.2 \times 10^{-8}$ & $1.58(1.35,1.84$ \\
\hline & rs11558471 (A) & 12 & 11 vs $120.96(0.67)$ & 0.96 & 0.86 & 0.58 & 0.52 & $3.5 \times 10^{-6}$ & $6.6 \times 10^{-5}$ & $1.25(1.11,1.41)$ & $1.7 \times 10^{-4}$ & $1.41(1.18,1.69)$ & $1.5 \times 10^{-4}$ & $1.35(1.16,1.59$ \\
\hline \multirow[t]{3}{*}{ PPARG } & rs180282 (G) & 13 & 13 vs $14: 0.87(0.079)$ & 0.30 & 0.78 & 0.06 & 0.05 & 0.394 & 7.482 & & & & & \\
\hline & rs12636454 (C) & 14 & 14 vs $15: 0.89(0.38)$ & 0.95 & 0.81 & 0.32 & 0.33 & 0.523 & 9.928 & & & & & \\
\hline & rs11128597 (A) & 15 & 13 vs $15: 0.70(0.022)$ & 0.14 & 0.43 & 0.48 & 0.46 & 0.296 & 5.618 & & & & & \\
\hline IGF2BP2 & rs4402960 (T) & 16 & & 0.46 & 0.53 & 0.23 & 0.22 & 0.176 & 3.335 & & & & & \\
\hline KCNJ11 & rs5215 (C) & 17 & & 0.21 & 0.28 & 0.42 & 0.41 & 0.225 & 4.277 & & & & & \\
\hline CDKN2A/ & rs564398 (C) & 18 & 18 vs $190.12(0.0011)$ & 0.00 & 0.27 & 0.01 & 0.01 & 0.627 & 11.913 & & & & & \\
\hline CDKN2B & rs10811661 (C) & 19 & & 0.26 & 0.56 & 0.05 & 0.05 & 0.880 & 1.670 & & & & & \\
\hline
\end{tabular}


tion for T2D association study of genetics, which was also supported by the allele frequency differences of SNPs in the significantly associated T2D genes among Han Chinese subpopulations from different parts of China, for instance, the C allele frequency of rs1326634 in SCL30A8 gene was 0.59 in cases and 0.54 in controls in this study compared to 0.42 in cases and 0.47 in controls in the study by Xiang et al. [23]. Therefore, this study not only replicated, but also complemented the previous studies of genetic variants and $\mathrm{T} 2 \mathrm{D}$ in the Chinese population.

Although rs7903146 in TCF7L2 was confirmed as the strongest T2D genetic variant in European original populations [14], the association of rs7903146 with T2D in east Asian populations, especially in China, remains unclear due to the low frequency of the risk allele of rs7903146 (<5\%). Miyake et al. demonstrated that SNP rs7903146 in the TCF7L2 gene was significantly associated with T2D in the Japanese population; the adjusted $\mathrm{p}$ value was 0.0011 in a study composed of 1,921 cases and 1,696 controls [14]. In another study dealing with the Japanese population, there was a marginal association between rs7903146 and T2D. The p value was 0.0485 in a cohort composed of 1,630 cases and 1,064 controls [34]. Although Chang, et al. did not find a signifcant association between rs7903146 and T2D in Taiwan Han Chinese populaiton study that included a p value of 0.36 (a study of 760 cases and 760 controls) [25], Maggie, et al. showed that rs7903146 was significantly associated with T2D in a Hong Kong Chinese population; the $\mathrm{p}$ value was 0.038 with 433 cases and 419 controls [26]. Ren, et al. also indicated that a trend association between rs7903146 and T2D with a p value of 0.063 in a study of 481 cases and 491 controls [24]. Our results further demonstrated that rs7903146 in the TCF7L2 gene was significantly associated with T2D in the Han Chinese population in mainland China; the T risk allele of rs7903146 conferred a 1.58 fold increasing the likelihood of having T2D, as compared with individuals who do not carry any of the four risk alleles (adjusted p $=1.0 \times 10^{-3}$, dominant model). This results was also supported by the meta- analysis of the association between rs7903146 in TCF7L2 gene and T2D in the four Han Chinese population(Table 2) and in the East Asian populations [31]. Given the factor of low MAF (minor allele frequency) of rs7903146 $(<5 \%)$, and the 5.5\% T2D prevalence in adults in China [26], a power calculation using an additive genetic model showed that approximately 1,500 cases and 1,500 controls would be necessary to achieve $80 \%$ power for rs 7903146 . This indicated that the sample size in some of the previous studies was underpowered in evaluating the association of rs7903146 and T2D in the Chinese populations $[24,25,27]$. Nevertheless, all studies redarding the association of TCF7L2 and T2D in Chinese populations indicated that other different genetic variants in the TCF7L2 gene showed a significant association with T2D in Chinese populations [20,24-26]. We also confirmed that another SNP rs6585205 in TCF7L2 gene was significantly associated with T2D in the studied cohort with an odd ratio of 1.31 (adjust $\mathrm{p}=4.0 \times 10^{-4}$, dominant model). Although it is certain that TCF7L2 plays an important role in the development of T2D in east Asian populations, it appears that the contribution of TCF7L12 to T2D development in east Asian populations is not as strong as that in Caucasian populations.

Consistent with previous findings [20,21,23,35], we also confirmed that SNPs in the CDKAL1, HHEX, and SLC30A8 genes showed a significant association with T2D in the Han Chinese population being studied. In this study, we found a significant association between all three SNPs typed, including rs1111875, rs7923837 and rs5015480, in the IDE-KIF11-HHEX region, and T2D in the Chinese population. Among the three SNPs in this region, rs7923837 showed the most significant association with T2D with an odds ratio of 1.39 (adjusted $\mathrm{p}=$ $8.62 \times 10^{-6}$, dominant model). The association is similar to that previously reported in Chinese populations [21], which further confirmed that the variants in this region play an important role in T2D for different races. However, the frequencies of risk alleles in the three SNPs were much lower in east Asian populations including China and Japan, than those reported in European original populations.

Among the four T2D associated genes, SNPs in CDKAL1 and SLC30A8 showed the most significant association with T2D in this study, and the significant association between the SNPs of both genes and T2D was observed all three models (multiplicative, dominant and recessive models) being tested. Only one SNP rs10946398 among the three SNPs we typed in CDKAL1 showed a significant association with T2D in this study, however this SNP showed to have the most significant association with T2D in all three models (multiplicative, dominant and recessive models) being tested among all nineteen SNPs we typed, indicating that the CDKAL1 gene may contribute more than the other three T2D-related genes in the development of T2D in Chinese patients being studied. All three SNPs, including rs13266634, rs3802177 and rs11558471 in the SLC30A8 gene were strongly associated with T2D in this study; however, rs3802177 had the most significant assocaition with T2D among the three SNPs with an adjusted p value of $1.22 \times 10^{-8}$ and an odd ratio of 1.58 when a recessive model was tested. The SLC30A8 gene plays the second important role among the four genes/loci in the development of T2D in Chinese Han population among the four T2D-related genes/loci in the study. However, these pre-mature conclusions require further investigaton in different Han Chinese populations.Although we could not replicate the signifi- 
cant association in the SNPs in the PPARG, IGF2BP2, $K C N J 11, E X T 2, C D K N 2 A / B$, and LOC387761 genes with T2D, which can be explained by investigating a different population in our study. In addition, we cannot exclude the possibility of the association of other SNPs in these genes/loci with T2D in the Han Chinese population. Further studies regarding other SNPs for these genes in large Chinese populaiotns are needed to answer these questions. Because T2D is one of the most common diseases, and there are many genes invloved in the development of this disorder, each gene represents a relatively small risk or protection when they are used to assess a disease threat in a patient.

\section{Conclusions}

We demonstrated that the genetic variants in TCF7L2, CDKAL1, HHEX, and SLC3OA8 were significantly associated with T2D in a different Han Chinese population from those of previous studies, further indicating that these gene/loci may play an important role in the development of T2D in the Han Chinese population. We further confirmed that TCF7L2 rs7903146 was significant association with T2D in the Han Chinese population.

\section{Additional material}

Additional file 1 Supplementary Table S1. PCR and SNaPshot primers of SNPs in the ten potential T2D genes/loci

\section{Abbreviations}

TCF7L2: Transcription factor 7-like 2; HHEX: Hematopoietically expressed homeobox; CDKAL1: CDK5 regulatory subunit associated protein 1-like 1; SLC30A8: Solute carrier family 30 (zinc transporter), member 8; PPARG: Peroxisome proliferator-activated receptor gamma; IGF2BP2: Insulin-like growth factor 2 mRNA binding protein 2; KCNJ11: Potassium inwardly-rectifying channel, subfamily J, member 11; EXT2: Exostoses (multiple) 2; CDKN2A/CDKN2B: Cyclin-dependent kinase inhibitor 2A/cyclin-dependent kinase inhibitor $2 \mathrm{~B}$; CAPN10: Calpain 10; ENPP1: Ectonucleotide pyrophosphatase/phosphodiesterase 1; HNF4A: Hepatocyte nuclear factor 4, alpha; ACDC: Pcyl-CoA dehydrogenase; PCR: Polymerase Chain Reaction; SBP: Systemic blood pressure; DBP: Diastole blood pressure; GLU: Glucose; TC: Total cholesterol; TG: Total triglyceride; LDL: Low-density lipoprotein; HDL: High-density lipoprotein; HBA1C: Glycosylated haemoglobin; ADAMTS9: ADAM metallopeptidase with thrombospondin type 1 motif, 9; THADA: thyroid adenoma associated; TSPAN8/LGR5: transmembrane 4 superfamily member 3/leucine-rich repeat-containing G protein-coupled; JAZF1: JAZF zinc finger 1; MTNR1B: melatonin receptor 1B; IRS: insulin receptor substrate 1; LD: Linkage disequilibrium; HWE: Hardy-Weinberg equilibrium

\section{Competing interests}

The authors declare that they have no competing interests.

\section{Authors' contributions}

Designed the study: $Y L$ and $Z Y$; collected samples and experiments: $Y L, P L, L C$, $X T, X Z, Y L, Y X, Y Y, L W, F L, X L, S R, M C, S M, Y S, M B, J W, Y Y, J Y$ and $Z Y$; performed the data analysis: $B Z, Y L$ and $Z Y$; writing the manuscript: $Z Y$. All authors read and approved the final manuscript.

\section{Acknowledgements}

We thank all participating patients and their families for their cooperation in this study. The authors wish to acknowledge the grant support of the Sichuan Academy of Medical Sciences \& Sichuan Provincial People's Hospital (Z. Yang), the Department of Science and Technology of Sichuan Province, China (Z. Yang, Y. Lin).

\section{Author Details}

${ }^{1}$ Center for Human Molecular Biology \& Genetics, Sichuan Academy of Medical Sciences \& Sichuan Provincial People's Hospital, Chengdu, Sichuan, China, Institute of laboratory Medicine, Sichuan Academy of Medical Sciences \& Sichuan Provincial People's Hospital, Chengdu, Sichuan, China and 3Department of Internal Medicine, Sichuan Academy of Medical Sciences \& Sichuan Provincial People's Hospital, Chengdu, Sichuan, China

Received: 19 September 2009 Accepted: 15 June 2010

Published: 15 June 2010

\section{References}

1. Boutayeb A, Boutayeb S: The burden of non communicable diseases in developing countries. Int J Equity Health 2005, 4(1):2

2. Altshuler D, Hirschhorn JN, Klannemark M, Lindgren CM, Vohl MC, Nemesh J, Lane CR, Schaffner SF, Bolk S, Brewer C, et al:: The common PPARgamma Pro12Ala polymorphism is associated with decreased risk of type 2 diabetes. Nat Genet 2000, 26(1):76-80.

3. Hara K, Boutin P, Mori Y, Tobe K, Dina C, Yasuda K, Yamauchi T, Otabe S, Okada T, Eto K, et al:: Genetic variation in the gene encoding adiponectin is associated with an increased risk of type 2 diabetes in the Japanese population. Diabetes 2002, 51(2):536-540.

4. Abate N, Chandalia M, Satija P, Adams-Huet B, Grundy SM, Sandeep S, Radha V, Deepa R, Mohan V: ENPP1/PC-1 K121Q polymorphism and genetic susceptibility to type 2 diabetes. Diabetes 2005, 54(4):1207-1213.

5. Yamagata K, Furuta H, Oda N, Kaisaki PJ, Menzel S, Cox NJ, Fajans SS, Signorini S, Stoffel M, Bell GI: Mutations in the hepatocyte nuclear factor4alpha gene in maturity-onset diabetes of the young (MODY1). Nature 1996, 384(6608):458-460.

6. Gloyn AL, Weedon MN, Owen KR, Turner MJ, Knight BA, Hitman G, Walker M, Levy JC, Sampson M, Halford S, et al:: Large-scale association studies of variants in genes encoding the pancreatic beta-cell KATP channel subunits Kir6.2 (KCNJ11) and SUR1 (ABCC8) confirm that the KCNJ11 E23K variant is associated with type 2 diabetes. Diabetes 2003 , 52(2):568-572.

7. Weedon MN, Schwarz PE, Horikawa Y, Iwasaki N, Illig T, Holle R, Rathmann W, Selisko T, Schulze J, Owen KR, et al:: Meta-analysis and a large association study confirm a role for calpain-10 variation in type 2 diabetes susceptibility. Am J Hum Genet 2003, 73(5):1208-1212.

8. Hanis $C L$, Boerwinkle E, Chakraborty R, Ellsworth DL, Concannon P, Stirling B, Morrison VA, Wapelhorst B, Spielman RS, Gogolin-Ewens KJ, et al.: A genome-wide search for human non-insulin-dependent (type 2) diabetes genes reveals a major susceptibility locus on chromosome 2 . Nat Genet 1996, 13(2):161-166.

9. Grant SF, Thorleifsson G, Reynisdottir I, Benediktsson R, Manolescu A, Sainz J, Helgason A, Stefansson H, Emilsson V, Helgadottir A, et al:: Variant of transcription factor 7-like 2 (TCF7L2) gene confers risk of type 2 diabetes. Nat Genet 2006, 38(3):320-323.

10. Sladek R, Rocheleau G, Rung J, Dina C, Shen L, Serre D, Boutin P, Vincent D, Belisle A, Hadjadj S, et al:: A genome-wide association study identifies novel risk loci for type 2 diabetes. Nature 2007, 445(7130):881-885.

11. Zeggini E, Weedon MN, Lindgren CM, Frayling TM, Elliott KS, Lango H, Timpson NJ, Perry JR, Rayner NW, Freathy RM, et al:: Replication of genome-wide association signals in UK samples reveals risk loci for type 2 diabetes. Science 2007, 316(5829):1336-1341.

12. Saxena R, Voight BF, Lyssenko V, Burtt NP, de Bakker PI, Chen H, Roix J Kathiresan S, Hirschhorn JN, Daly MJ, et al:: Genome-wide association analysis identifies loci for type 2 diabetes and triglyceride levels. Science 2007, 316(5829):1331-1336.

13. Scott LJ, Mohlke KL, Bonnycastle LL, Willer CJ, Li Y, Duren WL, Erdos MR, Stringham HM, Chines PS, Jackson AU, et al:: A genome-wide association study of type 2 diabetes in Finns detects multiple susceptibility variants. Science 2007, 316(5829):1341-1345.

14. McCarthy MI, Zeggini E: Genome-wide association studies in type 2 diabetes. Curr Diab Rep 2009, 9(2):164-171

15. Genome-wide association study of 14,000 cases of seven common diseases and 3,000 shared controls. Nature 2007, 447(7145):661-678. 
16. Salonen JT, Uimari P, Aalto JM, Pirskanen M, Kaikkonen J, Todorova B, Hypponen J, Korhonen VP, Asikainen J, Devine C, et al:: Type 2 diabetes whole-genome association study in four populations: the DiaGen consortium. Am J Hum Genet 2007, 81(2):338-345.

17. Steinthorsdottir $V$, Thorleifsson $G$, Reynisdottir I, Benediktsson $R$, Jonsdottir T, Walters GB, Styrkarsdottir U, Gretarsdottir S, Emilsson V, Ghosh S, et al:: A variant in CDKAL1 influences insulin response and risk of type 2 diabetes. Nat Genet 2007, 39(6):770-775.

18. Unoki H, Takahashi A, Kawaguchi T, Hara K, Horikoshi M, Andersen G, Ng DP, Holmkvist J, Borch-Johnsen K, Jorgensen T, et al:: SNPs in KCNQ1 are associated with susceptibility to type 2 diabetes in East Asian and European populations. Nat Genet 2008, 40(9):1098-1102.

19. Rung J, Cauchi S, Albrechtsen A, Shen L, Rocheleau G, Cavalcanti-Proenca C, Bacot F, Balkau B, Belisle A, Borch-Johnsen K, et al:: Genetic variant near IRS1 is associated with type 2 diabetes, insulin resistance and hyperinsulinemia. Nat Genet 2009, 41(10):1110-1115.

20. Wu Y, Li H, Loos RJ, Yu Z, Ye X, Chen L, Pan A, Hu FB, Lin X: Common variants in CDKAL1, CDKN2A/B, IGF2BP2, SLC30A8, and HHEX/IDE genes are associated with type 2 diabetes and impaired fasting glucose in a Chinese Han population. Diabetes 2008, 57(10):2834-2842.

21. Ng MC, Park KS, Oh B, Tam CH, Cho YM, Shin HD, Lam VK, Ma RC, So WY, Cho YS, et al:: Implication of genetic variants near TCF7L2, SLC30A8, HHEX, CDKAL1, CDKN2A/B, IGF2BP2, and FTO in type 2 diabetes and obesity in 6,719 Asians. Diabetes 2008, 57(8):2226-2233.

22. Zhou D, Zhang D, Liu Y, Zhao T, Chen Z, Liu Z, Yu L, Zhang Z, Xu H, He L: The E23K variation in the KCNJ11 gene is associated with type 2 diabetes in Chinese and East Asian population. J Hum Genet 2009.

23. Xiang J, Li XY, Xu M, Hong J, Huang Y, Tan JR, Lu X, Dai M, Yu B, Ning G: Zinc transporter-8 gene (SLC30A8) is associated with type 2 diabetes in Chinese. J Clin Endocrinol Metab 2008, 93(10):4107-4112.

24. Ren $Q$, Han XY, Wang F, Zhang XY, Han LC, Luo YY, Zhou XH, Ji LN: Exon sequencing and association analysis of polymorphisms in TCF7L2 with type 2 diabetes in a Chinese population. Diabetologia 2008, 51(7):1146-1152.

25. Chang YC, Chang TJ, Jiang YD, Kuo SS, Lee KC, Chiu KC, Chuang LM: Association study of the genetic polymorphisms of the transcription factor 7-like 2 (TCF7L2) gene and type 2 diabetes in the Chinese population. Diabetes 2007, 56(10):2631-2637.

26. Gu D, Reynolds K, Duan X, Xin X, Chen J, Wu X, Mo J, Whelton PK, He J: Prevalence of diabetes and impaired fasting glucose in the Chinese adult population: International Collaborative Study of Cardiovascular Disease in Asia (InterASIA). Diabetologia 2003, 46(9):1190-1198.

27. Ng MC, Tam CH, Lam VK, So WY, Ma RC, Chan JC: Replication and identification of novel variants at TCF7L2 associated with type 2 diabetes in Hong Kong Chinese. J Clin Endocrinol Metab 2007, 92(9):3733-3737.

28. Alberti KG, Zimmet PZ: New diagnostic criteria and classification of diabetes--again? Diabet Med 1998, 15(7):535-536.

29. Emigh T: A comparison of tests for Hardy-Weinberg equilibrium. Biometrics 1980, 36:627-642.

30. Lewis CM: Genetic association studies: design, analysis and interpretation. Brief Bioinform 2002, 3(2):146-153.

31. Luo $Y$, Wang $H$, Han $X$, Ren Q, Wang F, Zhang $X$, Sun $X$, Zhou X, Ji L: Metaanalysis of the association between SNPs in TCF7L2 and type 2 diabetes in East Asian population. Diabetes Res Clin Pract 2009, 85(2):139-146.

32. Xu S, Yin X, Li S, Jin W, Lou H, Yang L, Gong X, Wang H, Shen Y, Pan X, et al:: Genomic dissection of population substructure of Han Chinese and its implication in association studies. Am J Hum Genet 2009, 85(6):762-774.

33. Abdulla MA, Ahmed I, Assawamakin A, Bhak J, Brahmachari SK, Calacal GC, Chaurasia A, Chen $\mathrm{CH}$, Chen J, Chen YT, et al:: Mapping human genetic diversity in Asia. Science 2009, 326(5959):1541-1545.

34. Hayashi T, Iwamoto Y, Kaku K, Hirose H, Maeda S: Replication study for the association of TCF7L2 with susceptibility to type 2 diabetes in a Japanese population. Diabetologia 2007, 50(5):980-984.

35. Liu Y, Yu L, Zhang D, Chen Z, Zhou DZ, Zhao T, Li S, Wang T, Hu X, Feng GY, et al:: Positive association between variations in CDKAL1 and type 2 diabetes in Han Chinese individuals. Diabetologia 2008, 51(11):2134-2137.

Pre-publication history

The pre-publication history for this paper can be accessed here: http://www.biomedcentral.com/1471-2350/11/97/prepub

doi: 10.1186/1471-2350-11-97

Cite this article as: Lin et al., Association study of genetic variants in eight genes/loci with type 2 diabetes in a Han Chinese population BMC Medical Genetics 2010, 11:97

\section{Submit your next manuscript to BioMed Centra and take full advantage of:}

- Convenient online submission

- Thorough peer review

- No space constraints or color figure charges

- Immediate publication on acceptance

- Inclusion in PubMed, CAS, Scopus and Google Scholar

- Research which is freely available for redistribution

Submit your manuscript at www.biomedcentral.com/submit
C Biomed Central 